NBER WORKING PAPER SERIES

\title{
THE LINK BETWEEN PUBLIC AND PRIVATE INSURANCE AND HIV-RELATED MORTALITY
}

\author{
Jay Bhattacharya \\ Dana Goldman \\ Neeraj Sood \\ Working Paper 9346 \\ http://www.nber.org/papers/w9346 \\ NATIONAL BUREAU OF ECONOMIC RESEARCH \\ 1050 Massachusetts Avenue \\ Cambridge, MA 02138 \\ November 2002
}

This project was supported by grant\#5-RO1-HS10846 from the Agency for Healthcare Research and Quality. We thank Alan Garber and Michael Chernew for helpful discussions. We are responsible for remaining errors. The views expressed herein are those of the authors and not necessarily those of the National Bureau of Economic Research.

(C) 2002 by Jay Bhattacharya, Dana Goldman, and Neeraj Sood. All rights reserved. Short sections of text, not to exceed two paragraphs, may be quoted without explicit permission provided that full credit, including (C) notice, is given to the source. 
The Link Between Public and Private Insurance and HIV-Related Mortality

Jay Bhattacharya, Dana Goldman, and Neeraj Sood

NBER Working Paper No. 9346

November 2002

JEL No. I0

\section{$\underline{\text { ABSTRACT }}$}

As policymakers consider expanding insurance coverage for HIV+ individuals, it is useful to ask if insurance has any effect on health outcomes; and, if so, whether public insurance is as efficacious as private insurance in preventing premature deaths among HIV+ patients. Using data from a nationally representative cohort of HIV-infected persons receiving regular medical care, we estimate the impact of different types of insurance on mortality in this population.

We find that ignoring observed and unobserved health status leads one to conclude (misleadingly) that insurance may not be protective for HIV patients. After accounting for observed and unobserved heterogeneity, insurance does protect against premature death, but private insurance is more effective than public coverage. The better outcomes associated with private insurance are attributable to the more restrictive prescription drug policies of Medicaid.

Jay Bhattacharya

Center for Primary Care and Outcomes Research

Stanford Medical School

117 Encina Commons

Stanford, CA 94305-6019

and NBER

jay@stanford.edu

Neeraj Sood

RAND

1700 Main Street

Santa Monica, CA 90401

sood@rand.org
Dana Goldman

RAND

1700 Main Street

Santa Monica, CA 90401

and NBER

dgoldman@rand.org 


\section{Introduction}

Most economic models treat health insurance as a hedge against financial risk from illness. However the benefits from health insurance are not limited to the avoidance of financial risk, additional benefits are derived from insurance's ability to make available medical care that would otherwise be unaffordable (Nyman, 1999). In fact, policymakers have often cited the lack of affordability of health care and consequent poor health outcomes for the uninsured as the primary reason for expanding health insurance coverage. This view has motivated many investigations of the link between health insurance and health, including a recent study by the Institute of Medicine (Institute of Medicine, 2002).

In their review of this literature, Levy and Meltzer (2001) found that most of these studies were flawed. There was no causal link between having health insurance and better health-rather, there were associations. Exceptional studies that use randomization or quasi-randomization to address causation have found either no or limited effects on health, depending on the population under investigation and the health measure used. One problem with asking the broader question of how insurance affect health is that it may just be too ambitious. The impact of insurance on health will obviously depend on circumstances; from a policy perspective, it might be more useful to ask what population can most benefit from insurance expansions (either public or private), and how this relationship changes with changes in medical treatment.

The treatment of human immunodeficiency virus (HIV) provides a useful case study. In 1995, the Food and Drug Administration approved the first protease inhibitor for treatment of HIV. When new viral particles break off from an infected cell, protease cuts long protein strands into the parts needed to assemble a mature virus. These drugs block the protease enzyme, and hence prevent new viral particles from maturing. Clinical trials and observational data soon confirmed their clinical usefulness in combination with older drugs (so-called highly active anti-retroviral therapy or HAART) in forestalling HIV-related mortality (Palella et al., 1998). After the introduction of protease inhibitors into clinical practice, age-adjusted death rates from HIV infection fell 25\% from 1995 to 1996 and 47\% from 1996 to 1997 (Center for Disease Control, 1998). ${ }^{1}$

\footnotetext{
${ }^{1}$ HAART is a combination therapy involving three types of drugs: nucleoside reverse
} 
HAART is expensive, costing on average about $\$ 13,000$ per year. Thus it is possible that health outcomes for HIV-infected persons will be very responsive to the availability of insurance. Indeed, in previous work, we found that insurance significantly reduced mortality in HIV + patients (Goldman et al., 2001). These results suggest that policies to expand insurance coverage to the uninsured HIV + population could save many lives. However, that paper treats insurance as a single category for computational ease. HIV+ patients have coverage either through private insurance or public insurancetypically Medicaid. Since these types of insurance differ in extent of coverage and provider reimbursement we would expect that they differ in the quality and intensity of treatment.

Several studies have examined the relationship between insurance type and service utilization among HIV+ patients (Fleishman et al., 1994; Horner et al., 1996; Joyce et al., 1998; Shapiro et al., 1999). Most of these studies find that the uninsured or publicly insured $\mathrm{HIV}+$ patients incur lower per diem charges, receive fewer procedures and are less likely to receive expensive drug therapy than privately insured HIV + patients with similar medical conditions. In addition, a majority of HIV patients covered by public insurance are required to demonstrate a disability to qualify for coverage. Thus, most patients with public insurance obtain coverage only in the advanced stage of disease. These differences in the intensity of treatment and timing of initiation of coverage among publicly and privately insured HIV + patients leads naturally to questions about how these insurance types differ in their efficacy in preventing premature HIV related deaths.

In this paper, we identify the causal effects of different types of insurance on mortality by analyzing observational data on a nationally representative sample of adult HIV + patients receiving care in the US. However, measuring the efficacy of insurance in observational data is complicated by the fact that insurance decisions might be correlated with unobserved differences in the health status of patients. Thus, to account for this endogenity of insurance choices we jointly estimate insurance decisions and mortality and allow for arbitrary correlation between insurance and mortality in a parametric setting. To identify the 'true' effect of different insurance types on mortality we use state policy variables that affect the ease with which patients' can ob-

transcriptase inhibitors, protease inhibitors, and non-nucleoside reverse transcriptase inhibitors. All regimens require at least three drugs, and the vast majority involve at least one protease inhibitor. 
tain public insurance and a state level variables for firm size that affects the likelihood of obtaining employer provided insurance as instruments. These variables are clearly related to patient insurance status, but should not directly affect death rates (except through insurance).

The next section describes the data used for this analysis. We then present our joint model of insurance and mortality and provide the details of our identification strategy. Following that, we present results from a reduced form model that treats insurance as exogenous and compare them to the results from our structural model. The final sections discuss the conclusions and limitations of our analysis.

\section{Data}

We use data from a nationally representative study of $\mathrm{HIV}+$ patients in care - the HIV Costs and Services Utilization Study (HCSUS). The HCSUS employed a multi-stage national probability sample design to identify HIV+ patients over 18 years old, who made at least one visit for regular care in the contiguous United States in January or February of 1996. It does not include HIV + patients whose only contact with the health care system was through military, prison, or emergency department facilities, or who have not made contact with the health care system for their HIV. HCSUS collected three rounds of interviews: baseline, a first follow-up and a second follow-up with a baseline response rate of $68 \%$ (Duan et al., 1999). The first follow-up interview was conducted with 2466 subjects between December 1996 and July 1997; and the second follow-up was conducted with 2267 subjects between August 1997 and January 1998. Much of the attrition between waves is due to mortality. Toward the end of data collection for the baseline survey, HAART entered clinical practice and disseminated widely as the first-followup survey was in the field. Thus, we use the first follow-up sample of 2466 subjects with covariates measured at first follow-up for our analysis.

We construct analytic weights to adjust the sample to the reference population. A respondent's analytic weight, which may be interpreted as the number of people in the population represented by that respondent, is the product of three patient-specific quantities - the sampling weight, the multiplicity weight, and the non-response weight. The sampling weight adjusts

for oversampling (of women, for example); the multiplicity weight adjusts for patients who could potentially enter the sample via multiple providers; 
and the non-response weight adjusts for differential cooperation (Duan et al., 1999). All analyses presented in this paper use these weights.

We use mortality one year after the interview date as our outcome variable. Mortality is based on data collected by HCSUS interviewers in the field, as well as from Equifax, Inc., a credit company that also tracks deaths in the United States. The main explanatory variable we are interested in is insurance type, which are derived from the HCSUS data. Table 1 shows the proportion of respondents on HAART by sources of insurance coverage. Table 1 shows that the majority of HIV + patients obtain coverage through either private insurance or Medicaid - 30\% of the respondents are covered by private insurance only, $28 \%$ are covered by Medicaid only, $16 \%$ are covered by both Medicaid and Medicare, and 18\% are uninsured. However there are sharp differences in the use of HAART by source of insurance coverage. HIV patients with private insurance only are more likely to be on HAART than patients with any public insurance coverage. This is despite the higher incidence of AIDS (more advanced disease) among patients with public insurance. Thus to account for this differential use of HAART we classify patients into three mutually exclusive insurance categories -private insurance only, (any) public insurance, no insurance. ${ }^{2}$

\section{Empirical Model of Insurance and Mortality}

Let $m_{i}^{*}$ represent an index function that measures the mortality propensity for $\mathrm{HIV}+$ patient $i$ one year after interview. We model this mortality propensity as a function of the insurance status of the individual, observed covariates, and and unobserved error:

$$
m_{i}^{*}=c_{1}+\gamma \times \text { insured }_{i}+\beta_{1}^{\prime} X_{i}-\varepsilon_{i}
$$

The vector $X_{i}$ represents observed exogenous covariates that determine mortality propensity, such as age, gender, and education. Mortality is also affected by insurance status, where private $_{i}$ represents whether the patient was covered by private insurance (only), and public $c_{i}$ represents whether the patient was covered by (any) public insurance. Mortality is also assumed

\footnotetext{
${ }^{2}$ We check the sensitivity of our results in an alternate specification where we exclude patients with Medicaid and private insurance, Medicare and private insurance, and Medicare only from the public insurance category as patients in these insurance categories had higher use of HAART than other patients in the public insurance category.
} 
to depend on an unobservable heterogeneity component, $\rho_{m, i}$ that will also relate to insurance choices. It is useful to think of this as unobserved health status or attitudes towards risk, and they are assumed to be orthogonal to the covariates $X_{i}$. There is also a random error $\varepsilon_{m, i}$ that is uncorrelated with $X_{i}$ and insurance choice. We want to consistently estimate the parameters $c_{1}, \beta_{1}, \gamma_{1}$ and $\gamma_{2}$, after accounting for the endogeneity of insurance status.

We define $m_{i}$ as an indicator variable that represents whether patient $i$ actually died one year after interview:

$$
m_{i}= \begin{cases}1 & \text { if } m_{i}^{*}>0 \\ 0 & \text { if } m_{i}^{*} \leq 0\end{cases}
$$

We assume that $\varepsilon_{m, i}$ are i.i.d standard normal errors, with zero mean and unit variance. This distributional assumption implies a probit model for $m_{i}$, where the probability of death, conditional on observed characteristics $\left\{\right.$ private $_{i}$, public $\left._{i}, X_{i}\right\}$ and unobserved characteristics $\rho_{m}$ is:

$$
\begin{aligned}
& \left.P\left[m_{i}=1 \mid \text { \{private }_{i}, \text { public }_{i}, X_{i}\right\}, \rho_{m}\right]= \\
& \quad \Phi\left(c_{1}+\gamma_{1} \text { private }_{i}+\gamma_{2} \text { public }_{i}+\beta_{1}^{\prime} X_{i}+\rho_{m, i}\right)
\end{aligned}
$$

Here, $\Phi($.$) is the cumulative distribution function for the standard normal$ distribution.

Patients choose among insurance types $j=\{$ private, public, uninsured $\}$ on the basis of a standard random indirect utility function:

$$
V_{j, i}^{*}=c_{j}+\beta_{j}^{\prime} Z_{i}+\rho_{j, i}+\varepsilon_{j, i}
$$

Here, $Z_{i}$ represents variables that determine insurance status including our set of instrumental variables (that is, variables that belong in the insurance equation, but not in the mortality equation); and $\rho_{j, i}$ is a patient-specific random intercept that reflects the patients' propensity for insurance status $j$ that is unobserved by the researcher. Again, this could be due to unobserved disease severity or preferences for risk. The parameters $c_{j}$ and $\beta_{j}$ are additional parameters to be estimated; and $\varepsilon_{j, i}$ represents the orthogonal error term.

Patients choose the insurance status that maximizes their indirect utility. We assume that $\varepsilon_{j, i}$ are independently and identically distributed according to the Type II extreme value distribution. This distributional assumption and normalizing $\left\{c_{\text {uninsured }}, \beta_{\text {unisured }}, \rho_{\text {uninsured }, i}\right\}$ to zero yields a multinomial logit model for insurance choice. 


$$
\begin{gathered}
\mathrm{P}\left[\text { private }_{i}=1 \mid Z_{i}, \rho_{\text {private }}, \rho_{\text {public }}\right]=\frac{\exp \left(c_{\text {private }}+\beta_{\text {private }}^{\prime} Z_{i}+\rho_{\text {private }, i}\right)}{1+\sum_{j \neq \text { uninsured }} \exp \left(c_{j}+\beta_{j}^{\prime} Z_{i}+\rho_{j, i}\right)} \\
\mathrm{P}\left[\text { public }_{i}=1 \mid Z_{i}, \rho_{\text {private }}, \rho_{\text {public }}\right]=\frac{\exp \left(c_{\text {public }}+\beta_{\text {public }}^{\prime} Z_{i}+\rho_{\text {public }, i}\right)}{1+\sum_{j \neq \text { uninsured }} \exp \left(c_{j}+\beta_{j}^{\prime} Z_{i}+\rho_{j, i}\right)}
\end{gathered}
$$

To complete the model and allow for correlation between mortality and insurance choices, we need to assume a joint distribution for the unobserved heterogeneity vector $\rho=\left(\rho_{m}, \rho_{\text {private }}, \rho_{\text {public }}\right)$. Our approach is semi parametric. We allow the unobserved heterogeneity in each equation to take one of three values -intuitively, there are three types of people that occur with probabilities $p_{1}, p_{2}$, and $1-p_{1}-p_{2}$. The effect of being a certain type has different effects on each outcome: $\left(\rho_{m}^{1}, \rho_{m}^{2}, \rho_{m}^{3}\right)$ for mortality, $\left(\rho_{\text {private }}^{1}, \rho_{\text {private }}^{2}, \rho_{\text {private }}^{3}\right)$ for private insurance, and $\left(\rho_{\text {public }}^{1}, \rho_{\text {public }}^{2}, \rho_{\text {public }}^{3}\right)$ for public insurance. For example, there is a $p_{1}$ probability that a person will be of the first type, which would imply realizations of $\rho_{m}^{1}$ for the propensity to die, $\rho_{\text {public }}^{1}$ for the propensity to have public insurance, and $\rho_{\text {private }}^{1}$ for the propensity to privately insurance.

This discrete factor distributional approach has several advantages over specifying a continuous parametric density for the unobserved heterogeneity vector. First, an incorrect specification of the parametric density function might lead to biased parameter estimates. The discrete factor density allows us to approximate any underlying distribution of heterogeneity. In fact, Monte Carlo studies show that discrete factor distributions with 2-4 points of support adequately model many distributions (Heckman, 2001; Mroz, 1999). Second, discrete factor models are computationally simpler than parametric models as they avoid multiple numerical integration in the construction of the likelihood function.

Since the mortality, public insurance, and private insurance equations have intercept terms, we normalize the mean of each heterogeneity component to be zero. This implies that the third point of support in each equation is not "free". 3 Thus we need to estimate 8 additional parameters: 2 points of

\footnotetext{
${ }^{3}$ For example, the third point of support $\rho_{m}^{3}$ in the mortality equation can be written as
} 
support in the mortality equation, 2 points of support in the private insurance equation, 2 points of support in the public equation, and 2 probabilities. The resulting variance-covariance matrix for the unobserved heterogeneity is:

$$
\begin{aligned}
& \operatorname{Var}\left(\rho_{m}, \rho_{\text {private }}, \rho_{\text {public }}\right)= \\
& {\left[\begin{array}{lll}
\sum_{k} p_{k}\left(\rho_{m}^{k}\right)^{2} & \sum_{k} p_{k} \rho_{m}^{k} \rho_{\text {private }}^{k} & \sum_{k} p_{k} \rho_{m}^{k} \rho_{\text {public }}^{k} \\
& \sum_{k} p_{k}\left(\rho_{\text {private }}^{k}\right)^{2} & \sum_{k} p_{k} \rho_{\text {private }}^{k} \rho_{\text {public }}^{k} \\
& \sum_{k} p_{k}\left(\rho_{\text {public }}^{k}\right)^{2}
\end{array}\right]}
\end{aligned}
$$

This model not only allows non-zero covariance across mortality and insurance propensities but also allows non-zero covariance between private and public insurance propensities. Thus our model relaxes the IIA assumption of standard multinomial logit model and allows completely general variancecovariance matrix. The key correlations in our model may thus be written as:

$$
\begin{aligned}
\operatorname{Corr}\left(\rho_{m}, \rho_{\text {private }}\right) & =\frac{\sum_{k} p_{k} \rho_{m}^{k} \rho_{\text {private }}^{k}}{\sqrt{\sum_{k} p_{k}\left(\rho_{m}^{k}\right)^{2} \sum_{k} p_{k}\left(\rho_{\text {private }}^{k}\right)^{2}}} \\
\operatorname{Corr}\left(\rho_{m}, \rho_{\text {public }}\right) & =\frac{\sum_{k} p_{k} \rho_{m}^{k} \rho_{\text {public }}^{k}}{\sqrt{\sum_{k} p_{k}\left(\rho_{m}^{k}\right)^{2} \sum_{k} p_{k}\left(\rho_{\text {public }}^{k}\right)^{2}}} \\
\operatorname{Corr}\left(\rho_{\text {private }}, \rho_{\text {public }}\right) & =\frac{\sum_{k} p_{k} \rho_{\text {private }}^{k} \rho_{\text {public }}^{k}}{\sqrt{\sum_{k} p_{k}\left(\rho_{\text {private }}^{k}\right)^{2} \sum_{k} p_{k}\left(\rho_{\text {public }}^{k}\right)^{2}}}
\end{aligned}
$$

We use maximum likelihood to estimate the parameters of our model. The problem is that we do not observe any patient's type and so we must integrate over all possible types (three in our model). However, conditional

a function of the other two points of support and the probabilities of each type, as follows:

$$
\begin{aligned}
& E\left(\rho_{m}\right)=0 \\
& \Rightarrow p_{1} \cdot \rho_{m}^{1}+p_{2} \cdot \rho_{m}^{2}+\left(1-p_{1}-p_{2}\right) \cdot \rho_{m}^{3}=0 \\
& \Rightarrow \rho_{m}^{3}=-\frac{p_{1} \cdot \rho_{m}^{1}+p_{2} \cdot \rho_{m}^{2}}{\left(1-p_{1}-p_{2}\right)}
\end{aligned}
$$


on a given type, the heterogeneity is known. The contribution of patient $i$ to the likelihood function is thus given by:

$$
\begin{aligned}
& l_{i}=\sum_{k=1}^{3} p_{k}\left(\mathrm{P}\left[m_{i}=1 \mid \rho_{m}^{k}\right]^{m_{i}}\right) \times\left(1-\mathrm{P}\left[m_{i}=1 \mid \rho_{m}^{k}\right]^{1-m_{i}}\right) \times \\
& \left(\mathrm{P}\left[\text { private }_{i}=1 \mid \rho_{\text {private }^{k}}\right]^{\text {private }_{i}}\right) \times\left(\mathrm{P}\left[\text { public }_{i}=1 \mid \rho_{\text {private }^{k}}^{k}\right]^{\text {public }_{i}}\right) \times \\
& \left(1-\mathrm{P}\left[\text { private }_{i}=1 \mid \rho_{\text {private }^{k}}\right]-\mathrm{P}\left[\text { public }_{i}=1 \mid \rho_{\text {private }^{k}}^{k}\right]\right)^{\left(1-\text { private }_{i}\right)\left(1-\text { public }_{i}\right)}
\end{aligned}
$$

We have 6 possible outcomes for the dependent variables in our sample: (dead/alive) $\mathrm{x}$ (none/private/public). To construct the contribution to the likelihood function for each set of outcomes, we first obtain the likelihood of observing that value of the dependent variables conditional on a realization $k$ of the unobserved heterogeneity $\rho^{k}=\left(\rho_{m}^{k}, \rho_{\text {private }}^{k}, \rho_{\text {public }}^{k}\right)$. We then integrate over all all possible realizations to get Equation (11). Finally we obtain the weighted log-likelihood function by summing the log-likelihood across individuals:

$$
\ln (L \mid \Gamma)=\sum_{i=1}^{N} w_{i} \ln \left(l_{i}\right)
$$

$\Gamma$ is the vector of model parameters; $w_{i}$ are the analytic weights and $N$ is the sample size. Because it is difficult to interpret the magnitude of the parameter estimates directly, we also report the relative impact of private and public insurance on average mortality. More precisely, we compute:

$$
\begin{aligned}
& \mathrm{RI} \text { (private) } \equiv \frac{\text { Average mortality private }}{\text { Average mortality not insured }}-1 \\
& =\frac{\sum_{i} \sum_{k} p_{k} \Phi\left(c_{1}+\gamma_{1}+\beta_{1}^{\prime} X_{i}+\rho_{m}^{k}\right)}{\sum_{i} \sum_{k} p_{k} \Phi\left(c_{1}+\beta_{1}^{\prime} X_{i}+\rho_{m}^{k}\right)}-1 \\
& \mathrm{RI} \text { (public) } \equiv \frac{\text { Average mortality public }}{\text { Average mortality not insured }}-1 \\
& =\frac{\sum_{i} \sum_{k} p_{k} \Phi\left(c_{1}+\gamma_{1}+\beta_{1}^{\prime} X_{i}+\rho_{m}^{k}\right)}{\sum_{i} \sum_{k} p_{k} \Phi\left(c_{1}+\beta_{1}^{\prime} X_{i}+\rho_{m}^{k}\right)}-1
\end{aligned}
$$




\section{Identification}

We use state Medicaid policies and average firm size as our instrumental variables to explain insurance status but not mortality (except via insurance status). Medicaid is the most common form of insurance for the HIV+ population in care, covering $46 \%$ of the population. HIV + patients can qualify for Medicaid through three distinct pathways.

First, patients who meet the state's income eligibility and family composition requirements for Aid to Families with Dependent Children (AFDC) as they existed on July 16, 1996 qualify for Medicaid coverage. Second, Supplemental Security Income (SSI) beneficiaries are automatically eligible for Medicaid in 38 states. The other states have different standards for eligibility either as a 209(b) state or a waiver state. Section 209(b) of the Social Security Amendments Act of 1972 allows States to include more restrictive definitions of "disability" and lower income and assets standards for Medicaid eligibility. Medicaid eligibility is also available through a "medically needy" program for individuals who meet Medicaid's disability criteria but have incomes that exceed the financial eligibility limit. The program allows individuals to "spend down" to Medicaid eligibility by deducting medical-related expenses from their reported income. States have the option to but are not required to establish a "medically needy" program. In addition, states vary in their income eligibility levels for the "medically needy" program. For each patient, we define the following four variables based on Medicaid eligibility rules in the state in which the patient is sampled:

- Medically-Needy Threshold: This is the state's income eligibility threshold for the medically-needy program expressed as a percentage of the federal poverty line ${ }^{4}$.

- AFDC Threshold: This is the State's income eligibility threshold for Aid to Families with Dependent Children (AFDC) eligibility in 1996 expressed as a percentage of the federal poverty line.

- $S S I<65 \%$ FPL (federal poverty line): This is an indicator variable for whether the state's income eligibility threshold for Medicaid eligibility

\footnotetext{
${ }^{4}$ States which did not institute a medically-needy program were coded as having an income threshold of zero percent
} 
through the "SSI" category was at least 10 percentage points lower than the federal guideline of 75 percent of the federal poverty line ${ }^{5}$.

- Average firm size: This is the average firm size in the state in which the patient was sampled as instrument for insurance status. Several studies have documented the strong positive association between firm size and employer provided insurance offers (Bundorf, 2002; Cantor et al., 1995; Employee Benefit Research Institute, 2001).

Distributional assumptions aside, as in all instrumental variable-based studies, the credibility of our study rests on the believability of our instruments. Our state policy instruments and average firm could fail in at least two ways. First, the estimators perform poorly if the instruments are only weakly correlated with the treatment variable - that is, insurance status (Nelson and Startz, 1990; Bound et al., 1995; Staiger and Stock, 1997). Thus, we report Wald statistics for the joint significance of our instruments in predicting insurance status. Second, our instruments might be correlated with unobserved determinants of mortality (like unmeasured health status variables). The assumption that an instrumental variable is uncorrelated with the outcome measure cannot be directly tested. For these reasons, some researchers have argued that IV estimates in this context should be viewed with caution (Bound et al., 1995).

However, in our application, it seems clear that patients have little direct influence at an individual level on state policies or firm size, so our state level instruments seem valid. This argument is not enough to establish exogeneity, however, if there are unobserved state-level variables that determine both health and insurance status. In that case, state policies would be endogenous in our model despite the lack of control by patients over these policies. In order to address this issue, we develop some indirect evidence that our instruments are not simply picking up differences in unobserved health across states. If the latter hypothesis were true, then one would expect to find that our state-level instruments predict the mortality of patients even in a non-HIV population.

To check this assumption, we estimate a logit model of one-year mortality using data from the Medicare Current Beneficiary Survey (MCBS). On the

\footnotetext{
${ }^{5}$ We coded this as a dummy variable as there were only a 4 states that implemented a significantly more restrictive eligibility standard than the federal guideline.
} 
right-hand side, this mortality model includes a sparse set of health status indicators, such as measures of Activities of Daily Living (ADLs) and a general health index, and our state-policy instruments. Since this elderly or disabled population is by definition insured by Medicare, our instruments should not predict their mortality unless they proxy for unobserved state-level effects. Table 2 reports the regression results and shows that our instruments are not statistically significant in the model, with odds ratios near one. Of course, these results do not prove that unobserved state effects are unimportant in the HCSUS population, but they are certainly suggestive. There is no good reason to expect that such effects should be present for $\mathrm{HIV}+$ patients when they are not present for the elderly or disabled.

\section{$5 \quad$ Results}

Descriptive means for all model variables are given in Table 3. Most of the variables are self-explanatory. In some models, we include measures of the lowest ever CD4+ t-lymphocyte cell count, a critical measure of the function of a patient's immune system. A depletion in these cells correlates strongly with the worsening of HIV disease and the risk of death (Fauci et al., 1998). In this paper, we categorize CD4+ counts into four categories, as shown in Table 3. Patients with CD4+ lymphocyte counts below 50 have a very poor prognosis in general; while those with counts above 500 are considered much healthier.

To illustrate the consequences of selection bias, we estimate a "naïve" probit model where insurance status is treated as an exogenous variable. Table 4 reports the results from the naïve models. In order to demonstrate the importance of including information on health status, we include two sets of estimates; one set with controls for disease progression, particularly CD4 cell count, and one without.

In the regression without severity controls, public insurance is associated with an increased probability of 1-year mortality, and the effect is statistically and substantively significant. This finding persists in the analysis with severity controls, although the effect is no longer significant. This finding is analogous to that of Lancaster and Intrator (1998) who also found the perverse result that health insurance increases the risk of death for HIV+ patients. In both the regression models, private insurance is associated with a decreased probability of death, however the effect size is statistically in- 
significant in both models.

Table 5 summarizes the results on the impact of insurance status on mortality. In general, the use of severity controls reduces the magnitude of the both public and private insurance effect substantially. For instance, the results without severity controls indicate that public insurance increases relative mortality by $168 \%$, including health status measures like CD4 cell count reduces this effect to $31 \%$, but it does not disappear. Similar results are obtained for the private insurance effect-private insurance decreases relative mortality by $9 \%$ without severity controls and by $46 \%$ with severity controls. We attribute these findings to a spurious correlation between severity of illness and insurance for HIV patients. The correlation between public insurance and severity of illness seems to be especially strong. A possible explanation is that the eligibility rules for Medicaid or Medicare require $\mathrm{HIV}+$ patients to demonstrate a "disability" - almost always associated with advanced disease.

The parameter estimates for the mortality equation (1) in the structural model are shown in Table 6 , along with the correlation between insurance status and mortality - equations (8) and (9) - and the correlation between public and private insurance - equation (10). Table 7 gives the parameter estimates for the private and public insurance equations and also reports the joint significance of the excluded instruments in equation (4). This is computed using a Wald statistic, since these are considered a test of the small sample bias associated with the IV estimator (Staiger and Stock, 1997).

Table 6 shows several important differences from the naïve results. First, we see that both private and public insurance decrease the likelihood of death. This is in sharp contrast to the results from the naïve model where public insurance was associated with a higher probability of death and private insurance had a statistically insignificant effect on mortality. This reversal in the effects of private and public insurance on mortality can be explained by the positive correlation between unobserved health status and insurance choice. For instance, our results show that unobserved mortality propensity and public insurance propensity are positively correlated (correlation coefficient 0.89 ). Similarly we also find positive correlation between unobserved mortality propensity and private insurance propensity, although the degree of correlation is much weaker than that for public insurance.

Second, the magnitude of the relative impact of insurance on mortality is greater for private insurance $(79 \%)$ than for public insurance $(66 \%)$ (shown in Table 5). These findings might be explained by the differential access to 
HAART among those with public and private insurance (shown in Table 1). The findings are also consistent with the fact that most respondents receive public insurance only when they demonstrate "disability" due to advanced disease -this might delay treatment for the publicly insured patients thus resulting in poorer outcomes than those for privately insured patients.

In an alternate model we excluded patients with Medicare and private insurance, Medicaid and private insurance and Medicare only from the public insurance categories. Since these patients had higher HAART use than others on public insurance we would expect that excluding these patients would increase the difference between the impact of public and private insurance on mortality. Our results, confirm this hypothesis - the relative impact of private insurance on mortality increases marginally to $80 \%$ and the relative impact of public insurance on mortality decreases to $63 \%$.

It is also interesting to note that private and public insurance propensities are positively correlated. This might be explained by unobserved characteristics such as risk aversion and poor health that increase the propensity for insurance, in general.

The results from the insurance equations in Table 7 show that the state level instruments are highly correlated with both private and public insurance choice and are jointly significant $(p<0.01)$. As expected, we find that higher average firm size is associated with higher likelihood of having private insurance. We also find that more generous Medicaid eligibility rules are associated with higher likelihood of public insurance coverage. However, contrary to our expectations the results indicate that higher AFDC threshold is associated with a lower likelihood of public insurance. Multi-collinearity between the three Medicaid policy variables, which reduces the power of our estimates, seems to be the most likely explanation for this result (correlation between AFDC threshold and Medically Needy threshold is 0.62). In an alternate specification in which we excluded other Medicaid policy variables, we find that AFDC threshold has the expected sign and higher AFDC threshold is associated with higher likelihood of public insurance.

\section{Conclusion}

Our main findings are that (1) ignoring observed and unobserved health status in our structural mortality equation leads one to conclude that insurance

\footnotetext{
${ }^{6}$ The full results from this model are available from the authors upon request.
} 
may not be protective for HIV patients, (2) after accounting for observed and unobserved heterogeneity, insurance does protect against death, and (3) private insurance is more effective than public insurance in protecting HIV patients.

The finding that insurance is protective surely is related to highly active anti-retroviral therapy. By July 1997, approximately $75 \%$ of the HCSUS sample had used a protease inhibitor or nonnucleoside reverse transcriptase inhibitor (Shapiro et al., 1999). This rapid proliferation in clinical practice is remarkable given the approval of the first protease inhibitor was only two years earlier, and the expense associated with these new drugs.

The finding that private insurance is more effective than public insurance in preventing premature HIV-related deaths might be explained by differences in the intensity of treatment and use of HAART. In the HCSUS, less than $5 \%$ of those with private insurance did not have drug coverage. But while all Medicaid programs provide prescription drug coverage to those who are categorically eligible, many states do not provide such coverage to the Medically-Needy ${ }^{7}$. Using program participation and income data in the HCSUS, we have estimated elsewhere that $30 \%$ of those with Medicaid coverage qualified through the Medically-Needy program. Thus we expect that many of the HIV+ population with Medicaid do not have coverage of HAART.

In addition, the differences in the effectiveness of private and public insurance might be explained by differences in the timing of initiation of coverage. Some private insurers may place limits on when it will cover HAART, but Medicaid limits can be quite severe. Many states place limits on how many prescriptions can be filled per month, and since HAART therapy alone averages 4.8 prescriptions, these can limit coverage for not only HAART but also drugs to treat opportunistic infections associated with advanced disease. Many of the drugs also required prior authorization that restricted use to advanced illness. The result is that privately insured patients are able to start treatment earlier in the disease than the publicly insured, and the latter often have no coverage at all. The results suggest that extending public insurance coverage to HIV + patients in the early stage of the disease and creating incentives to increase treatment intensity and the use of HAART might prevent a significant number of premature HIV related deaths. These findings are especially relevant in light of the fact that treatment of HIV with prescription drugs not only saves lives but also result in lower total health care costs as

\footnotetext{
${ }^{7}$ Currently, 39 states offer drug coverage to the medically-needy.
} 
increases in pharmaceutical costs are offset by reduction in hospitalization and other related costs. 


\section{References}

Bound, J., Jaeger, D., and Baker, R. (1995). Problems with instrumental variables estimation when the correlation between the instruments and the endogenous explanatory variable is weak. Journal of the American Statistical Association, 90(430):443-450.

Bundorf, K. (2002). Employee demand for health insurance and employer health plan choices. Journal of Health Economics, 21(1):65-88.

Cantor, C., Long, S., and Marquis, S. (1995). Private employment-based health insurance in ten states. Health Affairs, 14(2):199-211.

Center for Disease Control (1998). Diagnosis and reporting of hiv and aids in states with integrated hiv and aids surveillance - united states, january 1994 - june 1997. Morbidity and Mortality Weekly Report, 47(15):309-314.

Duan, N., McCaffrey, D. F., Frankel, M. R., St. Clair, P. A., Beckman, R., Keesey, J. W., Chien, C., Goldman, D. P., Smith, S., and Morton, S. C. (1999). Hcsus baseline methods technical report: Weighting, imputation and variance estimation. RAND Report MR-1060-AHCPR, RAND, Santa Monica, CA.

Employee Benefit Research Institute (2001). Sources of health insurance and characteristics of the uninsured: Analysis of the march 2001 current population survey. EBRI Issue Brief \#240.

Fauci, A., Braunwald, E., Isselbacher, K., and Martin, J., editors (1998). Harrison's Principles of Internal Medicine, 14th Edition. New York: McGraw Hill.

Fleishman, J., Hsia, D., and Hellinger, F. (1994). Correlates of medical service utilization among people with hiv infection. Health Services Research, $29(5): 527-538$.

Goldman, D., Bhattacharya, J., McCaffrey, D., Duan, N., Leibowitz, A., Joyce, G., and Morton, S. (2001). The effect of insurance on mortality in an hiv+ population in care. Journal of the American Statistical Association, 96(405):883-894. 
Heckman, J. (2001). Micro data, heterogeneity, and the evaluation of public policy: Nobel lecture. Journal of Political Economy, 109:673-748.

Horner, R., Bennett, C., Achenbach, C., Rodriguez, D., Adams, J., Gilmann, S., Cohn, S., Dickinson, G., DeHovitz, J., and Weinstein, R. (1996). Predictors of resource utilization for hospitalized patients with pneumocystis carinii pneumonia (pcp): A summary of effects from the multi-city study of quality of pcp care. Journal of Acquired Immune Deficiency Syndromes and Human Retrovirology, 12:379-385.

Institute of Medicine (2002). Care Without Coverage: Too Little, Too Late. Institute of Medicine.

Joyce, G., Goldman, D., Leibowitz, A., Duan, N., Carlisle, D., Shapiro, M., and Bozzette, S. (1998). Variation in inpatient resource use in the treatment of hiv - do the privately insured receive more care? Medical Care, 37(3):220-227.

Lancaster, T. and Intrator, O. (1998). Panel data with survival: Hospitalization of hiv-positive patients. Journal of the American Statistical Association, 93(441):46-53.

Levy, H. and Meltzer, D. (2001). What do we really know about whether health insurance affects health? Working Paper \#274, Joint Center for Poverty Research.

Mroz, T. (1999). Discrete factor approximations in simultaneous equation models: Estimating the impact of a dummy endogenous variable on continuous outcomes. Journal of Econometrics, 92(2):233-274.

Nelson, C. R. and Startz, R. (1990). Some further results on the exact small sample properties of the instrumental variable estimator. Econometrica, 58(4):967-976.

Nyman, J. (1999). The value of health insurance: The access motive. Journal of Health Economics, 18(2):141-152.

Palella, F., Delaney, K., Moorman, A., Loveless, M., Fuhrer, J., Satten, G., Aschman, D., Holmberg, S., and The HIV Outpatient Study Investigators (1998). Declining morbidity and mortality among patients with 
advanced human immunodeficiency virus infection. New England Journal of Medicine, 338(13):853-60.

Shapiro, M. F., Morton, S. C., McCaffrey, D. F., Andersen, R. M., Berk, M. L., Bing, E. G., Cleary, P. D., Cunningham, W. E., Fleishman, J. A., Kanouse, D. E., Senterfitt, J. W., and Bozzette, S. A. (1999). Variations in the care of hiv-infected adults in the united states. results from the hiv cost and services utilization study. Journal of the American Medical Association, 281:2305-2315.

Staiger, D. and Stock, J. H. (1997). Instrumental variables regression with weak instruments. Econometrica, 65(3):557-586. 
Table 1: Insurance, Use of HAART, and AIDS

\begin{tabular}{|l|c|c|c|}
\hline Insurance status & \% of Sample & $\begin{array}{c}\text { HAART by first } \\
\text { followup (\%) }\end{array}$ & AIDS (\%) \\
\hline \hline None & 18 & 32 & 21 \\
\hline Public & 52 & 34 & 53 \\
Medicaid Only & 28 & 33 & 47 \\
Medicaid and Medicare & 16 & 33 & 58 \\
Medicaid and Private & 2 & 42 & 57 \\
Medicare Only & 4 & 43 & 64 \\
Medicare and Private & 2 & 53 & 62 \\
\hline Private (only) & 30 & 50 & 34 \\
\hline
\end{tabular}

Source: HCSUS first follow-up $(\mathrm{N}=2466)$. 
Table 2: Medicare beneficiary 1-year mortality-logit regression

\begin{tabular}{|l|c|c|c|}
\hline & & \multicolumn{2}{|c|}{$95 \%$ Conf. Interval } \\
Variables & Odds Ratio & Lower Limit & Upper Limit \\
\hline \hline State Instruments & & & \\
Medically-Needy Threshold & 1.001 & 0.997 & 1.004 \\
AFDC Threshold & 1.001 & 0.997 & 1.003 \\
SSI Threshold < 65\% of FPL & 1.140 & 0.816 & 1.592 \\
Average Firm Size & 0.985 & 0.924 & 1.050 \\
\hline Number of ADL limitations & & & \\
No Limitation (Ref. cat.) & - & - & - \\
1 ADL & 2.375 & 1.803 & 3.129 \\
2 ADL & 2.503 & 1.819 & 3.443 \\
3 ADL & 3.296 & 2.307 & 4.723 \\
4 ADL & 3.376 & 2.331 & 4.889 \\
5 ADL & 5.857 & 4.347 & 7.893 \\
6 ADL & 7.589 & 5.786 & 9.954 \\
\hline Self reported Health Status & & & \\
Excellent (Ref. Cat) & - & - & - \\
Very Good & 1.625 & 1.042 & 2.536 \\
Good & 1.839 & 1.205 & 2.805 \\
Fair & 2.415 & 1.574 & 3.703 \\
Poor & 4.283 & 2.7726 & 6.618 \\
\hline
\end{tabular}

Source: Medicare Current Beneficiary Survey, $1996(\mathrm{~N}=9,968)$. Excludes states not included in the HCSUS sample. 
Table 3: Descriptive Statistics

\begin{tabular}{|c|c|}
\hline Variable & $\begin{array}{l}\text { Proportion or mean } \\
\quad(\mathrm{N}=2,466)\end{array}$ \\
\hline $\begin{array}{l}\text { Insurance Status } \\
\text { Private Insurance } \\
\text { Public Insurance } \\
\text { Uninsured }\end{array}$ & $\begin{array}{l}30 \% \\
52 \% \\
18 \%\end{array}$ \\
\hline $\begin{array}{l}\text { Demographics } \\
\text { Age } \\
\text { Nonwhite } \\
\text { Female }\end{array}$ & $\begin{array}{c}39 \text { years } \\
51 \% \\
23 \%\end{array}$ \\
\hline $\begin{array}{l}\text { Education } \\
\text { Less than HS degree } \\
\text { High school degree } \\
\text { Some College or more }\end{array}$ & $\begin{array}{l}25 \% \\
27 \% \\
48 \%\end{array}$ \\
\hline $\begin{array}{l}\text { Years since diagnosis: } \\
\text { Less than one year } \\
1-2 \text { years } \\
2-3 \text { years } \\
3-4 \text { years } \\
4-5 \text { years } \\
5+\text { years }\end{array}$ & $\begin{array}{c}9 \% \\
12 \% \\
23 \% \\
27 \% \\
18 \% \\
11 \%\end{array}$ \\
\hline $\begin{array}{l}\text { State Instruments } \\
\text { Medically-Needy Threshold } \\
\text { AFDC Threshold } \\
\text { SSI Threshold }<65 \% \text { of FPL } \\
\text { Average Firm Size }\end{array}$ & $\begin{array}{c}50 \% \text { of FPL } \\
181 \% \text { of FPL } \\
7 \% \\
147 \text { workers }\end{array}$ \\
\hline $\begin{array}{l}\text { Lowest ever CD4 count (cells per } \mathrm{mm}^{3} \text { ) } \\
500+ \\
200-499 \\
50-200 \\
0-50\end{array}$ & $\begin{array}{c}8 \% \\
38 \% \\
31 \% \\
23 \%\end{array}$ \\
\hline Died within 12 months after interview & $4 \%$ \\
\hline
\end{tabular}

Note: FPL - Federal Poverty Line;

Source: HCSUS first followup survey $(\mathrm{N}=2,466)$ 
Table 4: Results for the naïve model

\begin{tabular}{|l|c|c|}
\hline Coefficient & $\begin{array}{c}\text { No severity } \\
\text { controls }\end{array}$ & $\begin{array}{c}\text { With severity } \\
\text { controls }\end{array}$ \\
\hline \hline Insurance & -0.0442 & -0.3071 \\
Private & $0.4521^{* *}$ & 0.1389 \\
Public & - & - \\
No Insurance (Ref. Cat.) & 0.0139 & -0.0098 \\
\hline Demographics & -0.0001 & 0.0003 \\
Age & -0.1327 & -0.1520 \\
Age & $-0.0516^{*}$ & 0.0154 \\
Nonwhite & & \\
Female & -0.0134 & -0.0075 \\
\hline Education & 0.0326 & -0.0568 \\
High school degree & - & - \\
Some College or more & & \\
Less than HS degree (Ref. Cat.) & 0.1836 & 0.0633 \\
\hline Years since diagnosis & 0.2441 & 0.3820 \\
Less than one year & -0.0200 & -0.0152 \\
1-2 years & $0.3746^{* *}$ & $0.4657^{* *}$ \\
2-3 years & 0.0761 & 0.1171 \\
$3-4$ years & - & - \\
$4-5$ years & & \\
$5+$ years (Ref. Cat.) & & $-0.9305^{* *}$ \\
\hline Lowest ever CD4 count \\
(cells per $m m^{3}$ ) & - & $-1.3007^{* *}$ \\
$500+$ & - & $-0.7420^{* *}$ \\
$200-499$ & - & - \\
\hline $50-200$ & - & -1.3810 \\
$0-50$ (Ref. Cat.) & $-5688^{* *}$ & \\
\hline Constant & & \\
\hline & & \\
\hline
\end{tabular}

Note: Estimates are from a single equation (weighted) probit of one-year mortality with and without severity controls $(\mathrm{N}=2,466)$.

** Statistically significant at $95 \%$ confidence level

* Statistically significant at $90 \%$ confidence level 
Table 5: Mortality Results (Deaths per 1,000 HIV+ patients)

\begin{tabular}{|l|c|c|c|}
\hline & \multicolumn{3}{|c|}{ Insurance Status } \\
& Private & Public & None \\
\hline \hline Unadjusted Raw Means & 19 & 63 & 26 \\
\hline Naïve Model & & & \\
No severity controls & $20(-9 \%)$ & $59(+168 \%)$ & 22 \\
With severity controls & $21(-46 \%)$ & $51(+31 \%)$ & 39 \\
\hline Structural Model & $25(-79 \%)$ & $41(-66 \%)$ & 120 \\
\hline
\end{tabular}

Note: Numbers in parentheses report percentage change in mortality relative to no insurance case (RI) for each empirical model (equations 13 and 14). 
Table 6: Structural Model-Mortality Equation

\begin{tabular}{|l|c|}
\hline Parameters & Estimate \\
\hline \hline Insurance & $-6.7153^{* * \#}$ \\
Private & $-5.2764^{* * \#}$ \\
Public & - \\
No Insurance (Ref. Cat.) & \\
\hline Demographics & -0.2059 \\
Age & 0.0032 \\
Age & -0.5536 \\
Nonwhite & 0.3652 \\
Female & \\
\hline Education & 0.4813 \\
High school degree & -0.5750 \\
Some College or more & - \\
Less than High School (Ref. Cat.) & \\
\hline Years since diagnosis & $-1.9967^{*}$ \\
Less than one year & -0.1727 \\
1-2 years & -0.9995 \\
2-3 years & -0.1966 \\
3-4 years & -0.2927 \\
$4-5$ years & - \\
$5+$ years $($ Ref. Cat.) & \\
\hline Lowest ever CD4 count & $-4.5941^{* *}$ \\
$500+$ cells per $m m^{3}$ & $-4.8722^{* *}$ \\
200 - 499 cells per $m m^{3}$ & $-3.5580^{* *}$ \\
$50-200$ cells per $m m^{3}$ & - \\
$0-50$ cells per $m m^{3}($ Ref. Cat.) & -0.6411 \\
\hline Constant & \\
\hline Correlations & 0.325 \\
Corr $\left(\rho_{m}, \rho_{\text {private }}\right)$ & 0.892 \\
Corr $\left(\rho_{m}, \rho_{\text {public }}\right)$ & 0.717 \\
Corr $\left(\rho_{\text {public }}, \rho_{\text {private }}\right)$ & \\
\hline
\end{tabular}

Note: Estimates are maximum likelihood estimates of equation $(12)(\mathrm{N}=2,466)$. Correlations are computed using equations (8)-(10).

** Statistically significant at $95 \%$ confidence level

* Statistically significant at $90 \%$ confidence level

\# Coefficient on private insurance is not equal to coefficient on public insurance at $95 \%$ confidence level 
Table 7: Structural Model—Insurance Equations

\begin{tabular}{|c|c|c|}
\hline Parameters & $\begin{array}{c}\text { Private } \\
\text { Insurance }\end{array}$ & $\begin{array}{c}\text { Public } \\
\text { Insurance }\end{array}$ \\
\hline \multicolumn{3}{|l|}{$\overline{\text { Demographics }}$} \\
\hline Age & $0.0932^{*}$ & -0.0143 \\
\hline $\mathrm{Age}^{2}$ & -0.0007 & 0.0007 \\
\hline Nonwhite & $-0.9247 * *$ & 0.0508 \\
\hline Female & -0.0141 & $0.7064^{* *}$ \\
\hline \multicolumn{3}{|l|}{ Education } \\
\hline High school degree & $0.8768^{* *}$ & -0.2089 \\
\hline Some College or more & $1.5504^{* *}$ & $-0.6675^{* *}$ \\
\hline Less than High School (Ref. Cat.) & - & - \\
\hline \multicolumn{3}{|l|}{ Years since diagnosis } \\
\hline Less than one year & $-1.0090 * *$ & $-1.4389 * *$ \\
\hline 1-2 years & -0.0787 & $-0.5448^{* *}$ \\
\hline $2-3$ years & -0.1152 & -0.4162 \\
\hline $3-4$ years & 0.0215 & -0.0699 \\
\hline $4-5$ years & 0.2848 & 0.2300 \\
\hline $5+$ years (Ref. Cat.) & - & - \\
\hline \multicolumn{3}{|l|}{ Lowest ever CD4 count } \\
\hline $500+$ cells per $m^{3}$ & $-0.8453^{* *}$ & $-1.8698^{* *}$ \\
\hline $200-499$ cells per $\mathrm{mm}^{3}$ & $-1.1291^{* *}$ & $-1.8803^{* *}$ \\
\hline $50-200$ cells per $m m^{3}$ & $-1.0054^{* *}$ & $-1.1391^{* *}$ \\
\hline \\
\hline $\begin{array}{l}\text { State-Level Instruments } \\
\text { SSI Threshold }<65\end{array}$ & -0.1179 & -0.1526 \\
\hline AFDC Threshold & $-0.0107^{*}$ & $-0.0142 * *$ \\
\hline Medically-Needy Threshold & $0.0167^{* *}$ & $0.0166^{* *}$ \\
\hline Average Firm Size & $0.1494^{* *}$ & 0.0461 \\
\hline Constant & -2.7945 & 3.6412 \\
\hline Wald test (of instruments) & $41.83^{* *}$ & $38.08^{* *}$ \\
\hline
\end{tabular}

Note: Estimates are maximum likelihood estimates of equation $(12)(\mathrm{N}=2,466)$. Correlations are computed using equations (8)-(10).

** Statistically significant at $95 \%$ confidence level

* Statistically significant at $90 \%$ confidence level

\# Coefficient on private insurance is not equal to coefficient on public insurance at $95 \%$ confidence level. 